\title{
Effect of Sex on the Association Between Nonmedical Use of Opioids and Sleep Disturbance Among Chinese Adolescents: A Cross-Sectional Study
}

\author{
Di Xiao ${ }^{1,2,3}$, Lan Guo ${ }^{1}$, Meijun Zhao ${ }^{1}$, Sheng Zhang ${ }^{1}$, Wenyan Li ${ }^{1}$, Wei-Hong Zhang ${ }^{2,4, *,+}$ \\ and Ciyong $\mathrm{Lu}^{1,3, *,+}$ \\ 1 Department of Medical Statistics and Epidemiology, School of Public Health, Sun Yat-sen University, \\ Guangzhou 510080, China; Di.Xiao@UGent.be (D.X.); guolan3@mail.sysu.edu.cn (L.G.); \\ zhaomj5@mail2.sysu.edu.cn (M.Z.); zhangsh46@mail2.sysu.edu.cn (S.Z.); liwy23@mail2.sysu.edu.cn (W.L.) \\ International Centre for Reproductive Health (ICRH), Department of Public Health and Primary Care, \\ Ghent University, 9000 Gent, Belgium \\ 3 Guangdong Provincial Key Laboratory of Food, Nutrition and Health, Sun Yat-sen University, \\ Guangzhou 510080, China \\ 4 Research Laboratory for Human Reproduction, Faculty of Medicine, Université Libre de Bruxelles (ULB), \\ 1050 Bruxelles, Belgium \\ * Correspondence: weihong.zhang@ugent.be (W.-H.Z.); luciyong@mail.sysu.edu.cn (C.L.); \\ Tel.: +86-20-8733-2477 (C.L.) \\ $\dagger$ These authors contributed equally to this work.
}

Received: 16 October 2019; Accepted: 5 November 2019; Published: 7 November 2019

\begin{abstract}
Sleep disturbance and non-medical prescription opioid use (NMPOU) are currently growing public health concerns, and sex differences may result in differential exposure to frequency of NMPOU or sleep disturbance. This study aimed to explore the association between the frequency of lifetime or past-year NMPOU and sleep disturbance and to evaluate whether there was any sex difference in this association among Chinese adolescents. A cross-sectional study was performed in seven randomly selected Chinese provinces through the 2015 School-Based Chinese Adolescents Health Survey. A total of 159,640 adolescents were invited to participate and among them, 148,687 adolescents' questionnaires were completed and qualified for this study (response rate: 93.14\%). All analyses were performed for boys and girls separately. There were significant sex differences in the prevalence of lifetime or past-year opioid misuse and sleep disturbance $(p<0.05)$. Among girls, frequent lifetime NMPOU (adjusted odds ratio $[\mathrm{aOR}]=2.09,95 \% \mathrm{CI}=1.80-2.44$ ) and past-year NMPOU $(\mathrm{aOR}=2.16,95 \% \mathrm{CI}=1.68-2.77)$ were positively associated with sleep disturbance. Among boys, these associations were also statistically significant, while the magnitudes of associations between frequent lifetime NMPOU or past-year NMPOU and sleep disturbance were greater in girls than those in boys. There is a significant sex difference in the prevalence of lifetime or past-year NMPOU and sleep disturbance. Furthermore, exposure to more frequent lifetime or past-year NMPOU is associated with a greater risk of sleep disturbance, especially among girls. Taking into account the sex difference for lifetime or past-year NMPOU may help to decrease the risk of sleep disturbance.
\end{abstract}

Keywords: non-medical prescription opioid use; sleep disturbance; sex differences; adolescents

\section{Introduction}

Sleep plays an important role in the development and maintenance of physical and mental health, especially in adolescents [1,2]. Evidence shows that sleep disruption is highly prevalent among adolescents [3]. Research in western countries has shown that approximately $25 \%-40 \%$ of adolescents 
have sleep disorders $[4,5]$. In China, it was estimated that the prevalence rate of sleep disturbance among adolescents ranged from $18.0 \%$ to $39.6 \%$ [6-8]. Recent studies have shown that sleep problems were associated with serious behavioral problems [9], depression [10], Attention-Deficit/Hyperactivity Disorder (ADHD) [11], poor school performance [12], and suicide [13] among children and adolescents. Sleep disturbance among adolescents has become a major international health concern.

The rise in non-medical prescription opioid use (NMPOU) is an emerging public health problem in adolescents [14]. Over the past two decades, the prevalence of prescription opioid misuse has increased more than threefold in the United States [15]. Most recent evidence from the National Survey on Drug Use and Health (NSDUH) showed that 3.5\% of adolescents aged 12 to 17 engaged in NMPOU in the past year [16]. Moreover, based on the data from the 2014 NSDUH, 7.3\% of responding adolescents aged 12-17 reported NMPOU during their lifetime [17]. A survey in China also found that NMPOU was prevalent among Chinese adolescents, and the prevalence of the lifetime NMPOU use was 7.7\% [18]. In China, the most commonly used medicine was licorice tablets with morphine, cough syrup with codeine, diphenoxylate, and tramadol [6]. Further, Guo et al. [19] reported that "to relax or relieve tension" was the most prevalent reason for nonmedical use of opioids among adolescents. The misuse of prescription opioids can lead to numerous adverse consequences, such as sexual behavior [20], heroin use [21], drug injection [21], depression [22], and suicidal behavior [23]. Evidence has shown that opioids can increase wakefulness and decrease total sleep time [24], delta sleep [25], sleep efficiency [25], and rapid eye movement (REM) sleep [26]. Walker et al. [27] reported a dose-dependent relationship between chronic opioid use and sleep disorders. Although there have been indications that past-month NMPOU could predict poor sleep [6], there is a dearth of studies addressing the potential association between the frequency of lifetime or past-year NMPOU and sleep disturbance in adolescents.

Sex differences may lead to differential exposure to prescription drug misuse or sleep disturbance. The prevalence of NMPOU in boys is reportedly greater than in girls [28,29], and girls complain more about their sleep than boys [30]. Research found that boys may have a stronger need for sensation-seeking than girls [31], and seeking pleasure and release of tension were the most common reasons for substance use [32,33]. Moreover, differences in the process of physiological changes related to puberty may lead to the sex differences in sleep disorders [34]. Whether the effects of lifetime or past-year NMPOU on sleep disturbance are similar or different for boys and girls is not clear and little attention has been paid to sex differences across these associations. Understanding the relationship between NMPOU and sleep disturbance among adolescents, as well as identifying the mechanisms that underlie potential sex differences may provide valuable insights and facilitate the design of sex-sensitive sleep disturbance preventive programs.

Therefore, to address the above questions, a large national study in China was conducted to assess the prevalence of lifetime NMPOU, past-year NMPOU, and sleep disturbance among Chinese adolescents; to explore the independent associations between the frequency of lifetime and past-year NMPOU with sleep disturbance; and to investigate whether there are sex differences within the associations.

\section{Materials and Methods}

\subsection{Study Design}

The cross-sectional data of the current study were collected from the 2015 School-based Chinese Adolescents Health Survey (SCAHS) [18,35]. SCAHS is an ongoing survey of health-related behaviors in 7th-12th grades students in China, which has been conducted every two years since 2007. The 2015 SCAHS is the most recent version [18].

\subsection{Data Collection and Sample}

Data collection procedures have been described in detail elsewhere [36]. Briefly, adolescents were selected using a multistage, stratified cluster sampling method. In stage 1, based on geographic 
location, a total of seven large provinces in China were selected. Each province was divided into three stratifications according to the Gross Domestic Product (GDP: high, medium, and low), then two cities were selected randomly from each stratus. In stage 2, from each representative city, the schools were classified according to three categories, including junior high school (grades 7-9), senior high school (grades 10-12), and vocational school (grades 10-12). We randomly selected 6 to 7 junior high schools, 4 to 5 senior high schools, and 2 to 3 vocational schools from each city. In stage 3, we randomly selected two classes from each grade and we investigated all the available students in these classes. Finally, a total of 159,640 adolescents were invited to participate in our survey, and 148,687 Chinese students completed the questionnaires (response rate: $93.14 \%$ ). To avoid any potential information bias, a Chinese-language self-administered questionnaire was completed by each student within one class period with the supervision of research assistants. To protect the privacy of the students, the questionnaire was completed anonymously and without a teacher present.

\subsection{Measures}

\subsubsection{Dependent Variable}

Sleep quality and disturbances over the past month were assessed by the Chinese version of the Pittsburgh Sleep Quality Index (PSQI). The Chinese version of the PSQI has been validated [37] and has been extensively used [8,38] with Chinese adolescents. The survey assessed the 19-item PSQI, which consists of seven components containing subjective sleep quality, sleep latency, sleep duration, habitual sleep efficiency, sleep disturbance, use of sleep medications, and daytime dysfunction. The sum of the scores for these seven components yields one global score with a range from 0 to 21, with higher scores indicating a higher level of sleep disturbance [37]. In China, a PSQI global score that is greater than 7 points indicates poor sleep quality, which is collectively known as sleep disturbance [7].

\subsubsection{Independent Variable}

In the present study, four opioid drugs were investigated: cough syrup compounded with codeine, compounded licorice tablets (opium), tramadol hydrochloride, and diphenoxylate. Lifetime NMPOU was measured by the following question: "Have you ever used the following list of prescription opioid drugs even once, when you were not sick or just for the intended purpose to experiment or to get high without a doctor's prescription?" The question was followed by a list of the above prescription opioid drugs, with responses coded as "never $=0$ ", "once or twice" $=1$, and "at least three times" $=2$. If the answer was "once or twice" or "at least three times", we then asked about the student's past-year NMPOU. Students who reported "never" were classified as abstainers, those who admitted once or twice were classified as experimenters, and those students who answered at least three times were classified as frequent users [19].

\subsubsection{Other Variables}

The demographic variables included age, sex (boy $=1$ and girl $=2)$, grade, academic pressure, academic achievement, classmate relationships, relationships with teachers, bullying experience, current smoking, and current drinking. Academic pressure and academic achievement were assessed by asking about the student's self-rating of his or her academic pressure or achievement relative to that of his or her classmates (responses were coded as "below average", "average", or "above average"). Relationships with teachers and classmate relationships were measured according to the students' self-rating of their relationships with their teachers and classmates (categorized into "good $=1$ ", "average $=2$ ", and "poor $=3$ ").

Bullying experience was measured with the Olweus Bully/Victim Questionnaire. The respondents were asked about the following question: "How often have you been bullied (kicked, intentionally excluded from participating, made fun of with sexual jokes, etc.) at school in the past 30 days?" [39]. The response options were (1) "never", (2) "sometimes or rarely (one or two times)", 
or (3) "often (more than three times)". Students who selected a frequency of "often" in the past 30 days were defined as being bullied [40].

Current smoking was investigated by asking students the following question: "How many days did you smoke cigarettes during the past 30 days?" Responses were defined as current smokers when the selected answers indicated 1 or more days [41]. Current drinking was assessed with the following question: "During the past 30 days, on how many days did you drink alcohol?" Responses were defined as current drinkers when the selected answers indicated 1 or more days [42].

\subsection{Ethical Considerations}

The Sun Yat-Sen University School of Public Health Institutional Review Board approved this study (L2014076). Then, a written informed consent form was obtained from each school and one of the parents (or legal guardians) of each participating adolescent after the study procedures had been fully described.

\subsection{Statistical Analysis}

SAS 9.4 (SAS Institute, Inc., Cary, NC, USA) was used to perform all statistical analyses. Firstly, to describe the sample characteristics, the prevalence of lifetime or past-year NMPOU, and sleep disturbance, descriptive analyses that were stratified by sex were conducted. Secondly, to investigate whether there were any statistically significant differences between female and male students, a t-test for continuous variables and chi-square test for categorical variables were performed. Thirdly, univariable logistic regression models were conducted to test the potential factors that are associated with sleep disturbance. Finally, multivariable logistic regression models were used to explore the independent associations of lifetime and past-year NMPOU with sleep disturbance, and the covariates that were associated $(p$ value $<0.05)$ with sleep disturbance in univariable analyses were entered simultaneously as control variables.

Statistical significance was set at the $p<0.05$ using two-sided tests.

\section{Results}

\subsection{Population Characteristics by Sex}

Table 1 presents the basic demographic information of this study. Of the 148,687 students, $48.0 \%$ $(71,442)$ were boys and $52.0 \%(77,245)$ were girls. The age range was $12-18$ years and the mean age of the students was 15.0 (SD: \pm 1.8 ). Overall, $1.8 \%$ and $0.7 \%$ of the students admitted that they were a "frequent user" of lifetime or past-year NMPOU, respectively. Among the total sample, $35.7 \%$ of the students rated their academic pressures as above average and $8.2 \%$ of the students had bullying experience. Approximately $5.3 \%$ of adolescents reported current smoking and $15.9 \%$ of the students currently drank alcohol. A total of $21.6 \%$ students reported having sleep disturbance. Statistically significant differences were observed in the sex distribution of age, grade, academic achievement, teacher-classmate and classmate relations, academic pressure, bullying experience, current smoking, current drinking, lifetime, and past-year NMPOU $(p<0.05)$.

Table 1. Sex difference of the sample characteristics $(n=148,687)$.

\begin{tabular}{ccccc}
\hline Variable & Total, No. $(\%)$ & Boys & Girls & $p$-Value ${ }^{\mathbf{1}}$ \\
\hline Total & 148,687 & $71,442(48.0)$ & $77,245(52.0)$ & $<0.001$ \\
\hline Age & & & & \\
12 to 13 & $34,890(23.5)$ & $16,844(23.6)$ & $18,046(23.4)$ & $<0.001$ \\
14 to 15 & $51,225(34.5)$ & $25,782(36.1)$ & $25,443(32.9)$ & \\
16 to 18 & $62,572(42.1)$ & $28,816(40.3)$ & $33,756(43.7)$ & \\
\hline
\end{tabular}


Table 1. Cont.

\begin{tabular}{|c|c|c|c|c|}
\hline Variable & Total, No. (\%) & Boys & Girls & $p$-Value ${ }^{1}$ \\
\hline \multicolumn{5}{|l|}{ Grade } \\
\hline 7 th to 9 th & $77,936(52.4)$ & $39,717(55.6)$ & $38,219(49.5)$ & $<0.001$ \\
\hline 10 th to 12 th & $70,751(47.6)$ & $31,725(44.4)$ & $39,026(50.5)$ & \\
\hline \multicolumn{5}{|c|}{ Academic achievement ${ }^{596}$} \\
\hline Above average & $52,839(35.7)$ & $24,364(34.2)$ & $28,475(37.0)$ & $<0.001$ \\
\hline Average & $49,782(33.6)$ & $21,172(29.7)$ & $28,610(37.2)$ & \\
\hline Below average & $45,470(30.7)$ & $25,651(36.0)$ & $19,819(25.8)$ & \\
\hline \multicolumn{5}{|c|}{ Teacher classmate relations 515} \\
\hline Good & $81,130(54.8)$ & $39,494(55.5)$ & $41,636(54.1)$ & $<0.001$ \\
\hline Average & $61,886(41.8)$ & $28,094(39.5)$ & $33,792(43.9)$ & \\
\hline Poor & $5156(3.5)$ & $3564(5.0)$ & $1592(2.1)$ & \\
\hline \multicolumn{5}{|l|}{ Classmate relations 465} \\
\hline Good & $108,178(73.0)$ & $52,656(74.0)$ & $55,522(72.1)$ & $<0.001$ \\
\hline Average & $37,389(25.2)$ & $16,873(23.7)$ & $20,516(26.6)$ & \\
\hline Poor & $2655(1.8)$ & $1664(2.3)$ & $991(1.3)$ & \\
\hline \multicolumn{5}{|l|}{ Academic pressure 182} \\
\hline Below average & $23,238(15.6)$ & $12,712(17.8)$ & $10,526(13.6)$ & $<0.001$ \\
\hline Average & $68,591(49.2)$ & $31,494(44.1)$ & $37,097(48.1)$ & \\
\hline Above average & $56,676(38.2)$ & $27,147(38.0)$ & $29,529(38.3)$ & \\
\hline \multicolumn{5}{|l|}{ Bullying experience } \\
\hline No & $136,458(91.8)$ & $63,204(88.5)$ & $73,254(94.8)$ & $<0.001$ \\
\hline Yes & $12,229(8.2)$ & $8238(11.5)$ & $3991(5.2)$ & \\
\hline \multicolumn{5}{|l|}{ Current smoking } \\
\hline No & $140,855(94.7)$ & $64,708(90.6)$ & 76,147 (98.6) & $<0.001$ \\
\hline Yes & $7832(5.3)$ & $6734(9.4)$ & $1098(1.4)$ & \\
\hline \multicolumn{5}{|l|}{ Current drinking } \\
\hline No & $125,120(84.1)$ & $56,357(78.9)$ & $68,763(89.0)$ & $<0.001$ \\
\hline Yes & $23,567(15.9)$ & $15,085(21.1)$ & $8482(11.0)$ & \\
\hline Lifetime NMPOU & & & & $<0.001$ \\
\hline Abstainers & $139,321(93.7)$ & $66,426(93.0)$ & $72,895(94.4)$ & \\
\hline Experimenters & $6679(4.5)$ & $3529(4.9)$ & $3150(4.1)$ & \\
\hline Frequent users & $2687(1.8)$ & $1487(2.1)$ & $1200(1.6)$ & \\
\hline Past-year NMPOU & & & & $<0.001$ \\
\hline Abstainers & 144,447 (97.1) & $69,139(96.8)$ & $75,308(97.5)$ & \\
\hline Experimenters & $3228(2.2)$ & $1738(2.4)$ & $1490(1.9)$ & \\
\hline Frequent users & $1012(0.7)$ & $565(0.8)$ & $447(0.6)$ & \\
\hline \multicolumn{5}{|l|}{ Sleep disturbance } \\
\hline No & $116,522(78.4)$ & $56,694(79.4)$ & $59,828(77.5)$ & $<0.001$ \\
\hline Yes & $32,165(21.6)$ & $14,748(20.6)$ & $17,417(22.5)$ & \\
\hline
\end{tabular}

NMPOU, non-medical prescription opioid use; Number of missing data were listed in superscript; ${ }^{1}$ Chi-square tests were used to test the association between the above-mentioned categories and sex.

\subsection{Prevalence of Sleep Disturbance by Sex}

Among boys and girls, the prevalence of sleep disturbance was $20.6 \%$ and $22.5 \%$, respectively (Table 1). Without adjusting for other variables, sleep disturbance was more prevalent among adolescents who were frequent lifetime NMPOU ( $36.2 \%$ among boys versus $41.8 \%$ among girls) and those with frequent past-year NMPOU (40.9\% among boys versus $47.0 \%$ among girls). Among both boys and girls, lifetime and past-year NMPOU, age, grade, academic achievement, teacher-classmate, classmate relations, academic pressure, bullying experience, current smoking, and current drinking were associated with sleep disturbance (Table 2). 
Table 2. Lifetime prevalence, crude odds ratios, and 95\% CI of sleep disturbance among adolescents: stratified by sex.

\begin{tabular}{|c|c|c|c|c|c|}
\hline \multirow{2}{*}{ Variable } & \multicolumn{5}{|c|}{ Sleep Disturbance } \\
\hline & Total $n(\%)$ & Boys $n(\%)$ & cOR $(95 \% \mathrm{CI})$ & Girls $n(\%)$ & cOR $(95 \% \mathrm{CI})$ \\
\hline \multicolumn{6}{|l|}{ Lifetime NMPOU } \\
\hline Abstainers & $29,153(20.9)$ & $13,263(20.0)$ & 1 & $15,890(21.8)$ & 1 \\
\hline Experimenters & $1972(29.5)$ & $946(26.8)$ & $1.49(1.36-1.62)$ & $1026(32.6)$ & $1.71(1.57-1.87)$ \\
\hline Frequent users & $1040(38.7)$ & $539(36.2)$ & $2.25(2.00-2.54)$ & $501(41.8)$ & $2.65(2.31-3.03)$ \\
\hline \multicolumn{6}{|c|}{ Past-year NMPOU } \\
\hline Abstainers & $30,720(21.3)$ & $14,033(20.3)$ & 1 & $16,687(22.2)$ & 1 \\
\hline Experimenters & $1004(31.1)$ & $484(27.8)$ & $1.50(1.33-1.70)$ & $520(34.9)$ & $1.90(1.67-2.16)$ \\
\hline Frequent users & $441(43.6)$ & $231(40.9)$ & $2.74(2.26-3.33)$ & $210(47.0)$ & $2.99(2.43-3.67)$ \\
\hline \multicolumn{6}{|l|}{ Age } \\
\hline 12 to 13 & $3763(10.8)$ & $1723(10.2)$ & 1 & $2040(11.3)$ & 1 \\
\hline 14 to 15 & $9838(19.2)$ & $4480(17.4)$ & $1.81(1.67-1.95)$ & $5358(21.1)$ & $2.11(1.94-2.29)$ \\
\hline 16 to 18 & $18,564(29.7)$ & 8545 (29.7) & $3.64(3.35-3.95)$ & $10,019(29.7)$ & $3.33(3.07-3.61)$ \\
\hline \multicolumn{6}{|l|}{ Grade } \\
\hline 7 th to 9 th & 11,097 (14.2) & $5328(13.4)$ & 1 & $5769(15.1)$ & 1 \\
\hline 10 th to 12 th & $21,068(30.0)$ & $9420(30.0)$ & $2.70(2.54-2.88)$ & $11,648(30.0)$ & $2.37(2.21-2.53)$ \\
\hline \multicolumn{6}{|c|}{ Academic achievement } \\
\hline Above average & $9762(18.5)$ & 4350 (17.9) & 1 & $5412(19.0)$ & 1 \\
\hline Average & $10,616(21.3)$ & $4194(19.8)$ & $1.15(1.08-1.22)$ & $6422(22.4)$ & $1.23(1.17-1.29)$ \\
\hline Below average & $11,704(25.7)$ & $6177(24.1)$ & $1.48(1.40-1.56)$ & 5527 (27.9) & $1.66(1.57-1.74)$ \\
\hline \multicolumn{6}{|c|}{ Teacher-classmate relations } \\
\hline Good & $13,605(16.8)$ & $6332(16.0)$ & $0.58(0.55-0.61)$ & $7273(17.5)$ & $0.55(0.53-0.58)$ \\
\hline Average & $16,327(26.4)$ & $6956(24.8)$ & 1 & $9371(27.7)$ & 1 \\
\hline Poor & $2145(41.6)$ & 1411 (39.6) & $1.92(1.75-2.10)$ & $734(46.1)$ & $2.21(1.95-2.50)$ \\
\hline \multicolumn{6}{|l|}{ Classmate relations } \\
\hline Good & $20,772(19.2)$ & $9668(18.4)$ & $0.61(0.58-0.64)$ & $11,104(20.0)$ & $0.62(0.59-0.65)$ \\
\hline Average & $10,288(27.5)$ & $4413(26.2)$ & 1 & $5875(28.6)$ & 1 \\
\hline Poor & $1018(38.3)$ & $621(37.3)$ & $1.64(1.45-1.86)$ & $397(40.1)$ & $1.69(1.44-1.98)$ \\
\hline \multicolumn{6}{|c|}{ Academic pressure } \\
\hline Below average & $2918(12.6)$ & $1701(13.4)$ & 1 & 1217 (11.6) & 1 \\
\hline Average & $10,706(15.6)$ & 4569 (14.5) & $0.62(0.55-0.69)$ & $6137(16.5)$ & $0.72(0.62-0.83)$ \\
\hline Above average & $18,517(32.7)$ & $8472(31.2)$ & $1.35(1.23-1.48)$ & $10,045(34.0)$ & $1.89(1.66-2.15)$ \\
\hline \multicolumn{6}{|c|}{ Bullying experience } \\
\hline No & $27,600(20.2)$ & $11,858(18.8)$ & 1 & $15,742(21.5)$ & 1 \\
\hline Yes & $4565(37.3)$ & $2890(35.1)$ & $2.38(2.24-2.54)$ & $1675(42.0)$ & $2.64(2.44-2.85)$ \\
\hline \multicolumn{6}{|l|}{ Current smoking } \\
\hline No & $29,223(20.7)$ & $12,328(19.1)$ & 1 & $16,895(22.2)$ & 1 \\
\hline Yes & $2942(37.6)$ & $2420(35.9)$ & $2.39(2.23-2.57)$ & $522(47.5)$ & $3.43(2.95-4.00)$ \\
\hline \multicolumn{6}{|l|}{ Current drinking } \\
\hline No & $24,382(19.5)$ & 10,107 (17.9) & 1 & $14,275(20.8)$ & 1 \\
\hline Yes & $7783(33.0)$ & $4641(30.8)$ & $2.01(1.90-2.12)$ & $3142(37.0)$ & $2.26(2.13-2.40)$ \\
\hline
\end{tabular}

NMPOU, non-medical prescription opioid use; cOR, crude odds ratio; $95 \% \mathrm{CI}$, $95 \%$ confidence interval.

\subsection{Association Between Lifetime or Past-Year NMPOU and Sleep Disturbance}

Table 3 and Figure 1 show the results of the final multivariable logistic regression models for sleep disturbance. After adjusting for age, grade, academic achievement, teacher-classmate and classmate relations, academic pressure, bullying experience, current smoking, and current drinking, lifetime and past-year NMPOU were significantly associated with sleep disturbance among both boys and girls. Among boys, frequent lifetime and past-year NMPOU was significantly associated with sleep disturbance, with aORs of 1.80 (95\% CI, 1.57-2.05) and 2.07 (95\%CI, 1.66-2.58), respectively. Among girls, frequent lifetime and past-year NMPOU were also positively associated with sleep disturbance, with aORs of 2.09 (95\% CI, 1.80-2.44) and 2.16 (95\%CI, 1.68-2.77), respectively. These results indicated that the associations between frequent lifetime and past-year NMPOU and sleep disturbance were 
higher among girls than boys. Moreover, the magnitudes of aORs for the significant associations between frequent lifetime or past-year NMPOU and sleep disturbance were greater than those between experimental use and sleep disturbance among both boys and girls.

Table 3. Adjusted odds ratios and $95 \% \mathrm{CI}$ for measuring the association between opioids use and sleep disturbance stratified by sex.

\begin{tabular}{ccc}
\hline \multirow{2}{*}{ Variable } & \multicolumn{2}{c}{ Sleep Disturbance } \\
\cline { 2 - 3 } & Boys, aOR (95\%CI) & Girls, aOR (95\%CI) $^{\mathbf{1}}$ \\
\hline Lifetime NMPOU & & 1 \\
Abstainers & 1 & $1.44(1.31-1.59)$ \\
Experimenters & $1.25(1.14-1.38)$ & $2.09(1.80-2.44)$ \\
Frequent users & $1.80(1.57-2.05)$ & 1 \\
\hline Past-year NMPOU & & $1.53(1.33-1.76)$ \\
Abstainers & 1 & $2.16(1.68-2.77)$ \\
Experimenters & $1.24(1.09-1.42)$ & \\
Frequent users & $2.07(1.66-2.58)$ &
\end{tabular}

NMPOU, non-medical prescription opioid use; aOR, adjusted odds ratio; $95 \% \mathrm{CI}, 95 \%$ confidence interval. ${ }^{1}$ Adjusted for age (years), grade, academic achievement, teacher-classmate, classmate relations, academic pressure, bullying experience, cigarette smoking, current drinking.
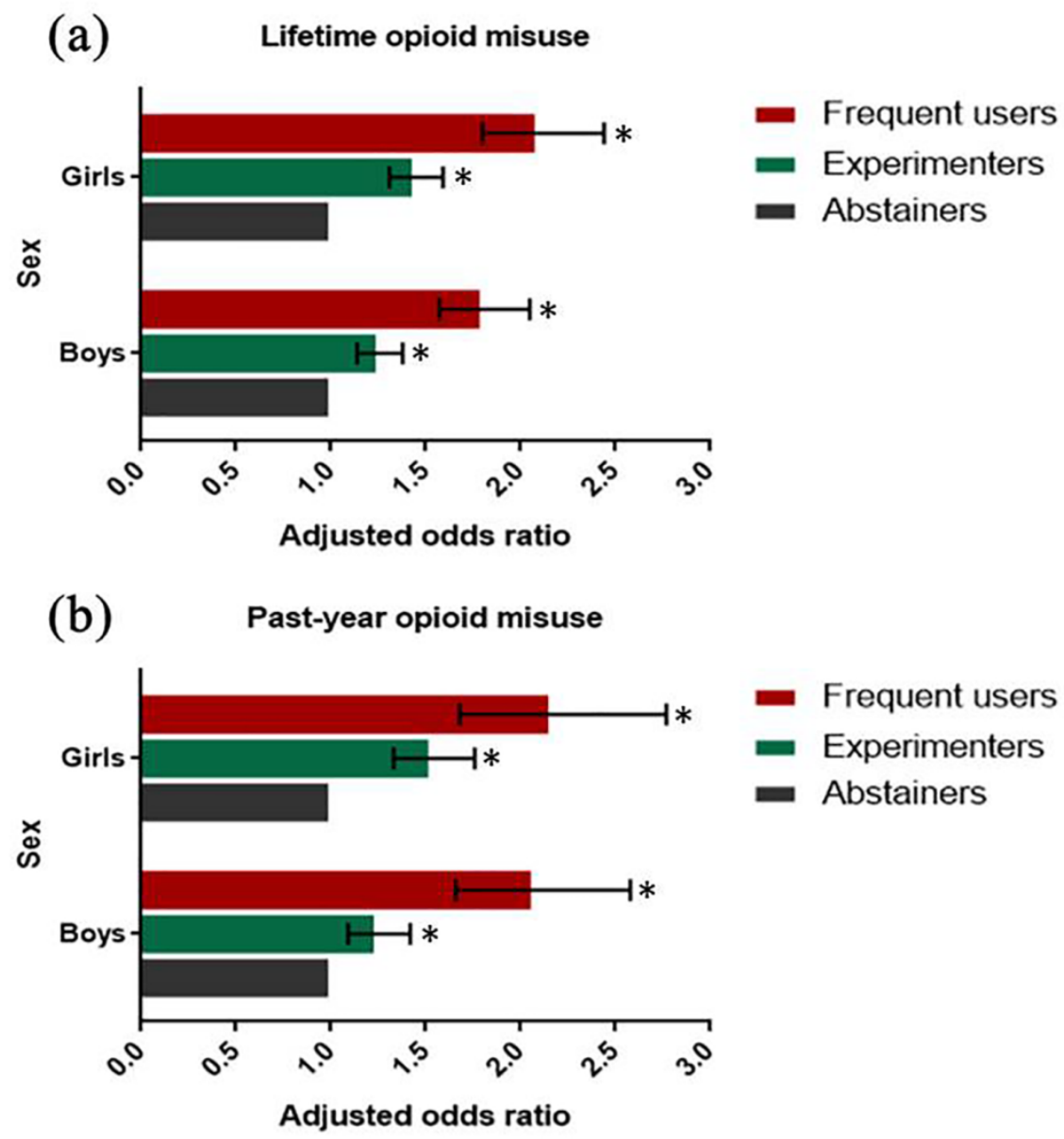

Figure 1. Adjusted OR and $95 \% \mathrm{CI}$ for measuring the association of lifetime or past-year NMPOU with sleep disturbance stratified by sex.* $p<0.05$. 


\section{Discussion}

\subsection{Main Findings}

This is the large-scale study aimed to investigate the influence of lifetime or past year NMPOU on adolescents' sleep disturbance. The present results demonstrate that $21.6 \%$ of the sampled students reported having sleep disturbance. This prevalence is higher than that measured in a study conducted in Hefei of China, which indicated that $18.6 \%$ adolescents admitted having sleep disturbance [43]. To date, the role of sex for sleep disturbance among adolescents is not well characterized. Moreover, data from individual studies on the sex differences in sleep disturbance are not entirely consistent [44-46]. For example, Hartley et al. [44] found that girls reported more sleeping problems than did boys, while Russo et al. [45] reported the opposite results. Moreover, Morrison et al. [46] found that there were no significant differences between boys and girls regarding their number of sleep problems. With the large sample, our results demonstrate a higher prevalence of sleep disturbance among girls compared to boys.

Our results also illustrated that lifetime NMPOU was prevalent among Chinese adolescents, and the prevalence was higher for boys than girls. Furthermore, this study indicated that boys were found to have higher prevalence rates of experimental and frequent use of opioids in their lifetime or the past year. This finding is consistent with a previous study, which found that nonmedical use of opioids was more prevalent in boys than girls [47]. Some evidence also supported that males generally reported more substance use than females [48]. The observed sex differences in susceptibility to nonmedical opioids use may be useful to enhance the design of sex-sensitive surveillance, identification, prevention, and treatment decisions toward NMPOU [49].

The univariate analyses found that younger girls were more likely to have sleep disturbances. Previous studies also suggested that girls' sleep problems are usually manifested at an earlier age than boys [30,50]. Different social requirements for boys and girls and differences in the process of physiological changes linked to puberty might account for the difference [30,51]. In addition, we observed that adolescents who reported having bullying experience were at a higher risk of sleep disturbance. Similarly, Zhou et al. [8] found that adolescents who were victims of bullying had a twofold increased risk of having sleep disturbances. Unsurprisingly, compared to their corresponding groups, students who reported current smoking or drinking had a higher risk of having sleep disturbances. Higher grades (10th to 12th), poor relationships with teachers or classmates, and higher academic pressure were positively associated with higher risk for sleep disturbance. In light of the growth of sleep disturbance and the host of adverse consequences that are linked with it, it is critical to recognize the high-risk students who will be more prone to sleep disturbance. Specifically, sex, age, grades, bullying experience, current smoking or drinking, relationships with teachers or classmates, academic pressure and achievement were showed to be differentially associated with sleep disturbance among adolescents. Gaining a better understanding of the nuances of sleep disturbance trends will support more refined health promotion efforts. Therefore, we suggested that clinicians, schools, and families should pay more attention to these high-risk students mentioned above with the adverse characteristics to reduce the potential risk of sleep disturbance.

Our findings provide some evidence that compared with experimental opioid misuse, more frequent prescription opioid misuse was associated with a greater likelihood of reporting sleep disturbance after adjusting for covariates. We speculated that compared to experimental users of opioids, individuals who reported more frequent opioid misuse are more likely to progress to dependent users who experience more interpersonal conflict, which then can contribute to triggering negative effects on physical health, ultimately leading to sleep disturbance [52].

Notably, another novel discovery of the study was the effects of the separate analyses by sex, which suggested that the adjusted associations between lifetime or past-year NMPOU and sleep disturbance appeared slightly higher in girls than boys. A possible explanation is that females who reported opioids misuse were found to have greater levels of global psychiatric and emotional 
distress $[53,54]$, and emotional trouble can lead to difficulty falling asleep in addition to further sleep disturbance [55].

\subsection{Limitations}

The limitations of the present study should be acknowledged when interpreting these findings. Firstly, it should be noted that a previous study found a bivariate relationship between the nonmedical use of prescription drugs and sleep among adolescents [56]. Furthermore, given the cross-sectional nature of the present study, our data cannot determine the exact timeline between lifetime or past-year NMPOU and sleep disturbance. Therefore, these issues should be further explored in a longitudinal study. Secondly, the data only included adolescents who were attending school, and on the day the survey was administered, adolescents who were not present at school or had dropped out of school were excluded. However, the anonymity of the questionnaires is assured and this method may have helped to collect accurate information from adolescents. Moreover, there could also be other potential confounders that were not included, such as mood disorders. Future surveys could collect the related information. Finally, our data only investigated the most widely used opioid drugs of Chinese adolescents. Hence, more prescription drugs need to be explored in future research.

Despite these limitations, the strength of the findings is that a large-scale sample of Chinese students was investigated, which ensures sufficient statistical power to measure the possible associations between lifetime or past-year NMPOU and sleep disturbance after adjusting for control variables. Besides, to our knowledge, the effect of sex on the association of lifetime or past-year NMPOU with sleep disturbance has not specifically been reported before. This is the first study that aimed to determine a sex-differential association among Chinese adolescents.

\subsection{Implications}

In China, NMPOU and sleep disturbance are both ongoing and rapidly evolving public health concerns. The findings clearly suggest that girls have a greater prevalence of sleep disturbance compared to boys and boys have a higher prevalence of experimental and frequent use of opioids in their lifetime and the past-year than girls. Furthermore, the study finds that although both boys and girls who reported lifetime or past-year NMPOU are at an increased risk of sleep disturbance, the association between frequency of opioid misuse and sleep disturbance is slightly stronger in girls. These results expand the areas of the literature, providing more specific information regarding the association between NMPOU and sleep disturbance. Also, the findings of this study highlight clinically relevant sex differences and may be helpful in guiding the design of sex-sensitive screening and treatment interventions for sleep disturbance [54]. Specific prevention and intervention programs are suggested: (1) to educate adolescents about avoiding the use of opioids as a way to deal with stress [57]; (2) to improve the awareness of the negative outcomes of NMPOU and sleep disturbance by educational campaigns; (3) to build a nation-wide active monitoring system to supervise NMPOU, sleep disturbance, and other health-risk behavior (e.g., smoking, drinking alcohol, and bulling victimization, etc.) among Chinese adolescents.

\section{Conclusions}

To conclude, this report identified sex differences in the prevalence of lifetime or past-year NMPOU. Moreover, exposure to more frequent lifetime or past-year NMPOU is associated with a greater risk of sleep disturbance, especially among girls. Future intervention or prevention strategies should take into account the sex difference on the effects of sleep disturbance among adolescent nonmedical-opioid users in China.

Author Contributions: Design, C.L. and L.G., Formal analysis, D.X.; Investigation, M.Z., S.Z., and W.L.; Data Cleaning, L.G. and D.X.; Writing—original draft, D.X.; Writing—review and editing, C.L. and W.-H.Z.; supervision, C.L. and W.-H.Z. 
Funding: This research was funded by the National Natural Science Foundation of China, grant number 81673252.

Acknowledgments: The authors are grateful for the local health professionals, the Department of Education, and the participating schools for their assistance and support. The authors also sincerely thank all the participants in our study.

Conflicts of Interest: The authors declare no conflict of interest.

\section{References}

1. Umlauf, M.G.; Bolland, A.C.; Bolland, K.A.; Tomek, S.; Bolland, J.M. The effects of age, gender, hopelessness, and exposure to violence on sleep disorder symptoms and daytime sleepiness among adolescents in impoverished neighborhoods. J. Youth Adolesc. 2015, 44, 518-542. [CrossRef]

2. Daly, B.P.; Jameson, J.P.; Patterson, F.; Mccurdy, M.; Kirk, A.; Michael, K.D. Sleep duration, mental health, and substance use among rural adolescents: Developmental correlates. J. Rural Ment. Health 2015, 39, 108-122. [CrossRef]

3. Colrain, I.M.; Baker, F.C. Changes in sleep as a function of adolescent development. Neuropsychol. Rev. 2011, 21, 5-21. [CrossRef]

4. Bailly, D.; Bailly-Lambin, I.; Querleu, D.; Beuscart, R.; Collinet, C. Sleep in adolescents and its disorders. A survey in schools. L'Encephale 2004, 30, 352-359. [CrossRef]

5. Garcia-Jimenez, M.A.; Salcedo-Aguilar, F.; Rodriguez-Almonacid, F.M.; Redondo-Martinez, M.P.; Monterde-Aznar, M.L.; Marcos-Navarro, A.I.; Torrijos-Martinez, M.P. The prevalence of sleep disorders among adolescents in Cuenca, Spain. Rev. Neurol. 2004, 39, 18-24. [PubMed]

6. Tang, D.; Li, P.; Guo, L.; Xu, Y.; Gao, X.; Deng, J.; Huang, J.; Huang, G.; Wu, H.; Yue, Y. The prevalences of and association between nonmedical prescription opioid use and poor sleep among Chinese high school students. Sci. Rep. 2016, 6. [CrossRef]

7. Guo, L.; Deng, J.; He, Y.; Deng, X.; Huang, J.; Huang, G.; Gao, X.; Lu, C. Prevalence and correlates of sleep disturbance and depressive symptoms among Chinese adolescents: A cross-sectional survey study. BMJ Open 2014, 4. [CrossRef] [PubMed]

8. Zhou, Y.; Guo, L.; Lu, C.; Deng, J.; He, Y.; Huang, J.; Huang, G.; Deng, X.; Gao, X. Bullying as a risk for poor sleep quality among high school students in China. PLoS ONE 2015, 10. [CrossRef]

9. Singh, G.K. Impact of neighborhood social conditions and household socioeconomic status on behavioral problems among US Children. Matern. Child Health J. 2012, 16, 158-169. [CrossRef] [PubMed]

10. Roberts, R.E.; Duong, H.T. The prospective association between sleep deprivation and depression among adolescents. Sleep 2014, 37, 239-244. [CrossRef]

11. Lunsford-Avery, J.R.; Krystal, A.D.; Kollins, S.H. Sleep disturbances in adolescents with ADHD: A systematic review and framework for future research. Clin. Psychol. Rev. 2016, 50, 159-174. [CrossRef]

12. Dewald, J.F.; Meijer, A.M.; Oort, F.J.; Kerkhof, G.A.; Bögels, S.M. The influence of sleep quality, sleep duration and sleepiness on school performance in children and adolescents: A meta-analytic review. Sleep Med. Rev. 2010, 14, 179-189. [CrossRef] [PubMed]

13. Goldstein, T.R.; Bridge, J.A.; Brent, D.A. Sleep disturbance preceding completed suicide in adolescents. J. Consult. Clin. Psychol. 2008, 76, 84-91. [CrossRef] [PubMed]

14. Lin, L.A.; Walton, M.A.; Bonar, E.E.; Blow, F.C. Trajectories of nonmedical use of prescription opioids among adolescents in primary care. Addict. Res. 2015, 24, 514-520. [CrossRef]

15. Hall, A.J.; Logan, J.E.; Toblin, R.L.; Kaplan, J.A.; Kraner, J.C.; Bixler, D.; Crosby, A.E.; Paulozzi, L.J. Patterns of abuse among unintentional pharmaceutical overdose fatalities. J. Am. Med. Assoc. 2008, 300, 2613-2620. [CrossRef] [PubMed]

16. Abuse, S.; Mental Health Services Administration. Key Substance Use and Mental Health Indicators in the United States: Results from the 2016 National Survey on Drug Use and Health; HHS Publication No. SMA 17-5044, NSDUH Series H-52; Center for Behavioral Health Statistics and Quality, Substance Abuse and Mental Health Services Administration: Rockville, MD, USA, 2017.

17. Hedden, S.L. Behavioral Health Trends in the United States: Results from the 2014 National Survey on Drug Use and Health; Substance Abuse and Mental Health Services Administration, Department of Heath \& Human Services: Rockville, MD, USA, 2015. 
18. Guo, L.; Xu, Y.; Deng, J.; Gao, X.; Huang, G.; Huang, J.; Deng, X.; Zhang, W.H.; Lu, C. Associations between childhood maltreatment and non-medical use of prescription drugs among Chinese adolescents. Addiction 2017, 112, 1600-1609. [CrossRef] [PubMed]

19. Guo, L.; Luo, M.; Wang, W.; Xiao, D.; Xi, C.; Wang, T.; Zhao, M.; Zhang, W.-H.; Lu, C. Association between nonmedical use of opioids or sedatives and suicidal behavior among Chinese adolescents: An analysis of sex differences. Aust. New Zealand J. Psychiatry 2019, 53, 559-569. [CrossRef]

20. Buttram, M.E.; Kurtz, S.P.; Surratt, H.L.; Levi-Minzi, M.A. Health and social problems associated with prescription opioid misuse among a diverse sample of substance-using MSM. Subst. Use Misuse 2014, 49, 277-284. [CrossRef] [PubMed]

21. Mateu-Gelabert, P.; Guarino, H.; Jessell, L.; Teper, A. Injection and sexual HIV/HCV risk behaviors associated with nonmedical use of prescription opioids among young adults in New York City. J. Subst. Abus. Treat. 2015, 48, 13-20. [CrossRef]

22. Edlund, M.J.; Forman-Hoffman, V.L.; Winder, C.R.; Heller, D.C.; Kroutil, L.A.; Lipari, R.N.; Colpe, L.J. Opioid abuse and depression in adolescents: Results from the National Survey on Drug Use and Health. Drug Alcohol Depend. 2015, 152, 131-138. [CrossRef]

23. Guo, L.; Xu, Y.; Deng, J.; Huang, J.; Huang, G.; Gao, X.; Wu, H.; Pan, S.; Zhang, W.H.; Lu, C. Association between nonmedical use of prescription drugs and suicidal behavior among adolescents. JAMA Pediatrics 2016, 170, 971-978. [CrossRef]

24. Kay, D.C.; Pickworth, W.B.; Neider, G.L. Morphine-like insomnia from heroin in nondependent human addicts. Br. J. Clin. Pharmacol. 2012, 11, 159-169. [CrossRef] [PubMed]

25. Pickworth, W.B.; Neidert, G.L.; Kay, D.C. Morphinelike arousal by methadone during sleep. Clin. Pharmacol. Ther. 1981, 30, 796-804. [CrossRef] [PubMed]

26. Ukponmwan, O. Sleep-Waking States and the Endogenous Opioid System; Erasmus University Rotterdam: Rotterdam, The Netherlands, 1986.

27. Walker, J.M.; Farney, R.J.; Rhondeau, S.M.; Boyle, K.M.; Valentine, K.; Cloward, T.V.; Shilling, K.C. Chronic opioid use is a risk factor for the development of central sleep apnea and ataxic breathing. J. Clin. Sleep Med. 2007, 3, 455-461. [PubMed]

28. Vaughn, M.G.; Nelson, E.J.; Salas-Wright, C.P.; Qian, Z.; Schootman, M. Racial and ethnic trends and correlates of non-medical use of prescription opioids among adolescents in the United States 2004-2013. J. Psychiatr. Res. 2016, 73, 17-24. [CrossRef] [PubMed]

29. Khooshabi, K.; Ameneh-Forouzan, S.; Ghassabian, A.; Assari, S. Is there a gender difference in associates of adolescents' lifetime illicit drug use in Tehran, Iran? Arch. Med. Sci. 2010, 6, 399-406. [CrossRef] [PubMed]

30. Ipsiroglu, O.S.; Fatemi, A.; Werner, I.; Paditz, E.; Schwarz, B. Self-reported organic and nonorganic sleep problems in schoolchildren aged 11 to 15 years in Vienna. J. Adolesc. Health 2002, 31, 436-442. [CrossRef]

31. Cross, C.P.; Cyrenne, D.L.; Brown, G.R. Sex differences in sensation-seeking: A meta-analysis. Sci. Rep. 2013, 3. [CrossRef]

32. Ahmadi, J.; Hasani, M. Prevalence of substance use among Iranian high school students. Addict. Behav. 2003, 28, 375-379. [CrossRef]

33. Galizio, M.; Stein, F.S. Sensation seeking and drug choice. Int. J. Addict. 1983, 18, 1039-1048. [CrossRef]

34. Krishnan, V.; Collop, N.A. Gender differences in sleep disorders. Curr. Opin. Pulm. Med. 2006, 12, $383-389$. [CrossRef] [PubMed]

35. Wang, H.; Deng, J.; Zhou, X.; Lu, C.; Huang, J.; Huang, G.; Gao, X.; He, Y. The nonmedical use of prescription medicines among high school students: A cross-sectional study in southern China. Drug Alcohol Depend. 2014, 141, 9-15. [CrossRef] [PubMed]

36. Li, P.; Huang, Y.; Guo, L.; Wang, W.; Xi, C.; Lei, Y.; Luo, M.; Pan, S.; Deng, X.; Zhang, W.H.; et al. Sexual attraction and the nonmedical use of opioids and sedative drugs among Chinese adolescents. Drug Alcohol Depend. 2018, 183, 169-175. [CrossRef] [PubMed]

37. Tsai, P.S.; Wang, S.Y.; Wang, M.Y.; Su, C.T.; Yang, T.T.; Huang, C.J.; Fang, S.C. Psychometric evaluation of the Chinese version of the Pittsburgh Sleep Quality Index (CPSQI) in primary insomnia and control subjects. Qual. Life Res. 2005, 14, 1943-1952. [CrossRef] [PubMed]

38. Yang, J.; Guo, Y.; Du, X.; Jiang, Y.; Wang, W.; Xiao, D.; Wang, T.; Lu, C.; Guo, L. Association between problematic Internet use and sleep disturbance among adolescents: The role of the child's sex. Int. J. Environ. Res. Public Health 2018, 15, 2682. [CrossRef] [PubMed] 
39. Olweus, D. The Olweus bully/victim questionnaire. Br. J. Educ. Psychol. 1996. [CrossRef]

40. Wu, J.; He, Y.; Lu, C.; Deng, X.; Gao, X.; Guo, L.; Wu, H.; Chan, F.; Zhou, Y. Bullying behaviors among Chinese school-aged youth: A prevalence and correlates study in Guangdong province. Psychiatry Res. 2015, 225, 716-722. [CrossRef]

41. Kandra, K.L.; Anna, M.C.; Leah, R.; Goldstein, A.O. Support among middle school and high school students for smoke-free policies, North Carolina, 2009. Prev. Chronic Dis. 2013, 10, 675-681. [CrossRef]

42. Huang, R.; Ho, S.Y.; Wang, M.P.; Lo, W.S.; Lam, T.H. Sociodemographic risk factors of alcohol drinking in Hong Kong adolescents. J. Epidemiol. Community Health 2015, 70, 374-379. [CrossRef]

43. Xu, Z.; Su, H.; Zou, Y.; Chen, J.; Wu, J.; Chang, W. Sleep quality of Chinese adolescents: Distribution and its associated factors. J. Paediatr. Child Health 2012, 48, 138-145. [CrossRef]

44. Hartley, S.L.; Sikora, D.M. Sex differences in autism spectrum disorder: An examination of developmental functioning, autistic symptoms, and coexisting behavior problems in toddlers. J. Autism Dev. Disord. 2009, 39. [CrossRef] [PubMed]

45. Russo, P.M.; Caponera, E.; Barbaranelli, C. Personality, sleep habits and sleep problems in a representative sample of Italian eighth grade students. Personal. Individ. Differ. 2014, 60, S65-S66. [CrossRef]

46. Morrison, D.N.; Mcgee, R.; Stanton, W.R. Sleep problems in adolescence. J. Am. Acad. Child Adolesc. Psychiatry 1992, 31, 94-99. [CrossRef]

47. Wang, J.; Deng, J.X.; Lan, G.; Yuan, H.; Xue, G.; Huang, J.H.; Huang, G.L.; Lu, C.Y. Non-medical use of psychoactive drugs in relation to suicide tendencies among Chinese adolescents. Addict. Behav. 2015, $51,31-37$.

48. Cotto, J.H.; Davis, E.; Dowling, G.J.; Elcano, J.C.; Staton, A.B.; Weiss, S.R. Gender effects on drug use, abuse, and dependence: A special analysis of results from the National Survey on Drug Use and Health. Gend. Med. 2010, 7, 402-413. [CrossRef]

49. Back, S.E.; Payne, R.L.; Simpson, A.N.; Brady, K.T. Gender and prescription opioids: Findings from the National Survey on Drug Use and Health. Addict. Behav. 2010, 35, 1001-1007. [CrossRef] [PubMed]

50. Lazaratou, H.; Dikeos, D.G.; Anagnostopoulos, D.C.; Sbokou, O.; Soldatos, C.R. Sleep problems in adolescence. A study of senior high school students in Greece. Eur. Child Adolesc. Psychiatry 2005, 14, 237-243. [CrossRef] [PubMed]

51. Murata, K.; Araki, S. Menarche and sleep among Japanese schoolgirls: An epidemiological approach to onset of menarche. Tohoku J. Exp. Med. 1993, 171, 21-27. [CrossRef]

52. Ashrafioun, L.; Bishop, T.M.; Conner, K.R.; Pigeon, W.R. Frequency of prescription opioid misuse and suicidal ideation, planning, and attempts. J. Psychiatr. Res. 2017, 92, 1-7. [CrossRef]

53. Luthar, S.S.; Gushing, G.; Rounsaville, B.J. Gender differences among opioid abusers: Pathways to disorder and profiles of psychopathology. Drug Alcohol Depend. 1996, 43, 179-189. [CrossRef]

54. Back, S.E.; Lawson, K.M.; Singleton, L.M.; Brady, K.T. Characteristics and correlates of men and women with prescription opioid dependence. Addict. Behav. 2011, 36, 829-834. [CrossRef] [PubMed]

55. Vandekerckhove, M.; Weiss, R.; Schotte, C.; Exadaktylos, V.; Haex, B.; Verbraecken, J.; Cluydts, R. The role of presleep negative emotion in sleep physiology. Psychophysiology 2011, 48, 1738-1744. [CrossRef] [PubMed]

56. Ayres, C.G.; Pontes, N.M.; Pontes, M.C.F. Understanding the nonmedical use of prescription medications in the U.S. high school adolescents. J. Sch. Nurs. 2017, 33, 269-276. [CrossRef] [PubMed]

57. Jamison, R.N.; Butler, S.F.; Budman, S.H.; Edwards, R.R.; Wasan, A.D. Gender differences in risk factors for aberrant prescription opioid use. J. Pain 2010, 11, 312-320. [CrossRef] [PubMed]

(C) 2019 by the authors. Licensee MDPI, Basel, Switzerland. This article is an open access article distributed under the terms and conditions of the Creative Commons Attribution (CC BY) license (http://creativecommons.org/licenses/by/4.0/). 